\title{
Numerical and Experimental Analysis of Wood Tensile Strength Perpendicular to the Grain
}

João Vítor Felippe Silva ${ }^{1}$

Patrik Luiz Silva de Araujo ${ }^{2}$ (D)

Karina Aparecida de Oliveira ${ }^{1}$

Maria Fernanda Felippe Silva ${ }^{2}$ (1)

Carolina Aparecida Oliveira ${ }^{1}$ (I)

Julio Cesar Molina ${ }^{2}$ (1)

${ }^{1}$ Universidade Estadual Paulista Júlio de Mesquita Filho (UNESP), Faculdade de Engenharia, Departamento de Engenharia Mecânica, Campus de Guaratinguetá, Guaratinguetá, SP, Brasil.

${ }^{2}$ Universidade Estadual Paulista Júlio de Mesquita Filho (UNESP), Campus Experimental de Itapeva, Itapeva, SP, Brasil.

\begin{abstract}
The Brazilian Code ABNT NBR 7190 (1997) is currently under review process and one of the proposals is the change and add of some test procedures. Several specimen geometric configurations and test conditions have been evaluated by the study committee CE-02:126.10. The aim of this paper was the analysis of the tensile strength perpendicular to the grain through the current Brazilian Code and from an adaptation of ISO 13910 (2005). Pine and Indian Cedar were used and simplified relationships were proposed. Numerical simulations were performed to identify the stress distributions in the specimens. The results obtained by ISO 13910 (2005) did not differ statistically for the two species. Brazilian standard method cedar had a higher strength value than pine. The simplified ratios obtained ranged between 0,017 and 0,123 . The numerical simulations of ISO 13910 (2005) specimens showed predominant failure by tension in the lower fiber due to stress concentration.
\end{abstract}

Keywords: Wood Strength, Mechanical Testing, Finite Element Method, Standardization.

\section{INTRODUCTION AND OBJECTIVES}

Wood is a natural material with variations in strength, elasticity, among other properties, which can occur as a function of the variation in the angle of the fibers, presence of defects, or even as a function of the percentage of moisture present in the wood (Rocha et al., 2018). Wood is also known for its orthotropic characteristics that result in different mechanical properties for the three different orthogonal directions considered (tangential, longitudinal, and radial) (Costa et al., 2020; Mascia et al., 2020).

The Brazilian Code for wood structures ABNT NBR 7190 (1997) is under review and, the test method PN 02:126.100001-3 contains the main test procedures for wooden specimens with structural dimensions. This test method is based on the ISO 13910 (2005) standard, and tests are required for the validation of this test procedure in Brazil.
Tests that have been carried out to characterize the mechanical properties of wood are based on defect-free specimens and with standardized dimensions, regardless of the type of wood used (Almeida et al., 2020; Costa et al., 2020). However, tests based on Annex B of ABNT NBR 7190 (1997) are recommended for native woods, while tests according to PN 02:126.10-0001-3 are related to reforestation woods with structural dimensions.

According to ABNT NBR 7190 (1997), the direction parallel to the grain is taken as a reference for determining the properties of wood. For use in structures, wood is chosen according to its strength class, which can vary between $20 \mathrm{MPa}$ and $60 \mathrm{MPa}$.

Thus, the specimen geometric configuration for the tension test perpendicular to the grain proposed by the ABNT NBR 7190 (1997) - Annex B, has been a matter of discussion when it is compared with the models proposed by other international standards, such as, ISO 13910 (2005) that provides different 
strength values for the same mechanical property considered (Tanaami, 1993; Matos \& Molina, 2016; Mascia et al., 2020). Based on the ABNT NBR 7190 (1997) standard, the specimen with standardized dimensions is subject to a single tension effort, and in the ISO 13910 (2005) standard, the specimen is tested in bending, combining tension, compression, and shear, to determine the tensile strength in the direction perpendicular to the grain (see Figure 1).
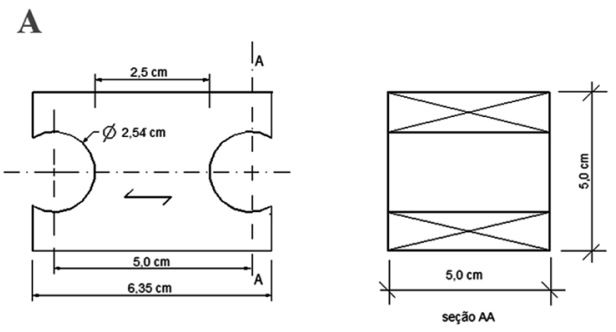

B

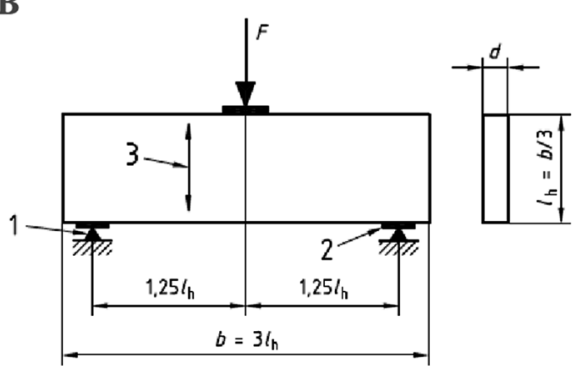

Figure 1. A - Defect-free specimen. Source: ABNT NBR 7190 (1997) - Annex B. B - Specimen with structural dimensions. Source: ISO 13910 (2005).

The knowledge of the tensile strength perpendicular to the grain is important to evaluate the mechanical performance of wood, especially in situations where these stresses are present, such as in CLT slabs and in some cases of MLC beams (Bidakov \& Raspopov, 2018; Wu et al., 2020). However, this thematic area of study still under discussion does not have many papers published (Tanaami, 1993; Schlotzhauer et al., 2019; Mascia et al., 2020).

Several tests have been carried out by the members of the study committee CE - 02:126.10, considering different international standards, in order to define more representative test methods and specimen geometric configurations for obtaining the mechanical wood properties.

The aim of this paper was the evaluation of two different specimen geometric configurations and normative test methods proposed by the Brazilian standards ABNT NBR 7190 (1997) and an adaptation of ISO 13910 (2005) to compare the results obtained by the two methods. Results on this type of comparison were not found in the literature. The simplified characterization ratio $\left(f_{t 90, k} / f_{c 0, k}\right)$ between the characteristic value of perpendicular tensile strength $\left(f_{t 90, k}\right)$ and the compression strength along the grain $\left(f_{c 0, k}\right)$ was also determined, since ABNT NBR 7190 (1997) does not present relationships involving these two properties. It was also evaluated the distribution of stresses in the test specimens tested through numerical simulation in ANSYS in order to justify the failure modes found in the experimental tests. This work is intended to give subsidies to the revision project of ABNT NBR 7190 (1997).

\section{MATERIALS AND METHODS}

\subsection{Experimental analysis}

Experimental tests were carried out to determine the tensile strength perpendicular to the grain and the compressive strength along the grain for two wood species: Indian Cedar (Acrocarpus fraxinifolius) and Pine (Pinus elliottii), both species currently used in the Brazilian wood industry (Reis et al., 2019). The moisture contents of the test specimens were determined based on ABNT NBR 7190 (1997). All strength tests were carried out with wood with moisture content in the range between $10 \%$ and $20 \%$. Subsequently, the strength values obtained in the tests have been corrected to standard 12\% moisture content according to Equation 1, recommended by ABNT NBR 7190 (1997).

$f_{t 90,12 \%}=f_{U \%} *\left[1+\frac{3 *(U \%-12)}{100}\right]$

Where:

$f_{\mathrm{t} 0,12 \%}=$ tensile strength of wood perpendicular to the grain at $12 \%$ moisture content, in MPa;

$f_{\mathrm{U} \%}=$ tensile strength of wood perpendicular to the grain at $\mathrm{U} \%$ moisture content, in $\mathrm{MPa}$;

$\mathrm{U} \%=$ moisture content of the specimen at the time of the mechanical test, in percentage.

Forty samples were tested for each wood species and standard method, totaling 160 specimens for determining the tensile strength perpendicular to the grain, 80 for the Brazilian standard, and another 80 for the standard ISO 13910 (2005).

The configurations and dimensions used for the specimens according to ISO 13910 (2005) and ABNT NBR 7190 (1997) are shown in Figure 2. Note that the direction of the fibers in the ISO 13910 (2005) specimens has been changed. 

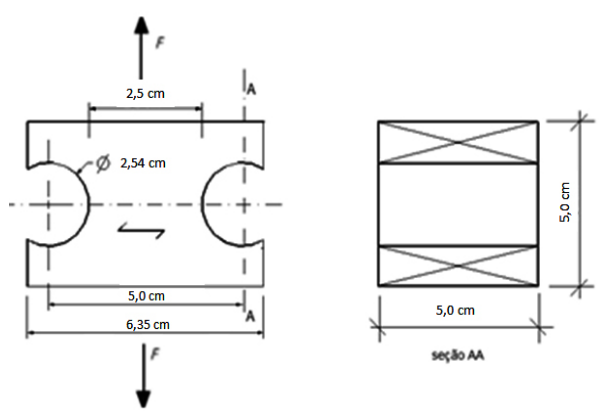

ABNT NBR 7190 (1997)

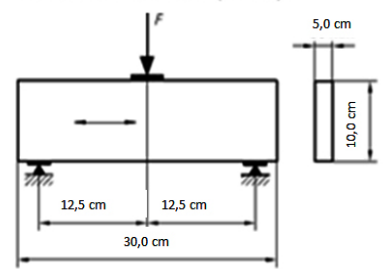

ISO 13910 (2005)

Figure 2. Configuration of test specimens to determine the tensile strength perpendicular to the grain based on the normative documents considered.

The specimens obtained from the ABNT NBR 7190 (1997) were tested in tension perpendicular to the grain and the specimens from the ISO 13910 (2005) were tested in bending. The specimens of compression parallel to the grain (Figure 2) were used to determine the simplified relationships $f_{\mathrm{t} 00, \mathrm{k}} / f_{\mathrm{c} 0 \mathrm{k}}$ between the characteristic tensile strength perpendicular to the grain $\left(f_{\mathrm{t} 90, \mathrm{k}}\right)$ and the characteristic compressive strength parallel to grain $\left(f_{c 0, k}\right)$. Six specimens were considered for each wood species (pine and cedar), totaling 12 compression specimens with standardized dimensions $(50 \times 50 \times 150 \mathrm{~mm})$, in accordance with the recommendations of the Brazilian standard ABNT NBR 7190 (1997).

To conduct the mechanical tests, the universal testing machine EMIC with a capacity of $300 \mathrm{kN}$ was used (see Figure 3). The loads on the specimens of perpendicular tension to the grain and of bending were applied at a speed of $2,5 \mathrm{MPa} / \mathrm{min}$. The compression tests were carried out with a loading rate of $10 \mathrm{MPa} / \mathrm{min}$.

The tensile strength normal to the grain $\left(f_{t 90}\right)$ according to the Brazilian standard was determined using Equation 2. A single load cycle was applied until the failure of the specimen. In Equation 2, $F_{\text {rup }}$ is the ultimate load reached by the specimen during the test and $A$ is the rupture area considered for the specimen.

$$
f_{t 90}=\frac{F_{\text {rup }}}{A}
$$

The normal tensile strength according to ISO 13910 (2005), was obtained from bending tests with concentrated loading applied in the middle of the span, based on Equation 3. The load was applied with a single cycle until the failure of the specimen. Parameters $d$ and $b$ are, respectively, the width and length of the bending specimen, $F_{\text {ult }}$ is the value of the ultimate load obtained in the test for the beam (Figure 3).

$f_{t, 90}=\left(\frac{3,75 * F_{u l t}}{d * b}\right) *\left(\frac{0,03 * 0,03 * d l_{h}{ }^{2}}{800^{3}}\right)^{0,2}$

The factor $\left(0.03 \cdot \mathrm{dl}_{\mathrm{h}}{ }^{2} / 800^{3}\right)^{0.2}$ normalizes the tensile strength to the equivalent value for a wooden cube with a side equal to $800 \mathrm{~mm}$.

The characteristic strength values for determining simplified relationships were obtained from Equation 4, proposed by the Brazilian standard ABNT NBR 7190 (1997). In equation $4, f_{1}, f_{2} \ldots f_{\mathrm{n}}$ are the strength values obtained in the tests, and $n$ is the number of specimens tested.

$f_{w, k}=\left(2 * \frac{f_{1}+f_{2}+f \frac{n}{2}-1}{\frac{n}{2}-1}-f_{\frac{n}{2}}\right) * 1,1$

The strength results perpendicular to the grain obtained from the experimental tests were analyzed based on statistical tests performed using the $\mathrm{R}$ software version 4.0.5. The statistical tests performed were: Bartlett's test, Shapiro-Wilk, and Tukey's test at a significance level of $5 \%$.

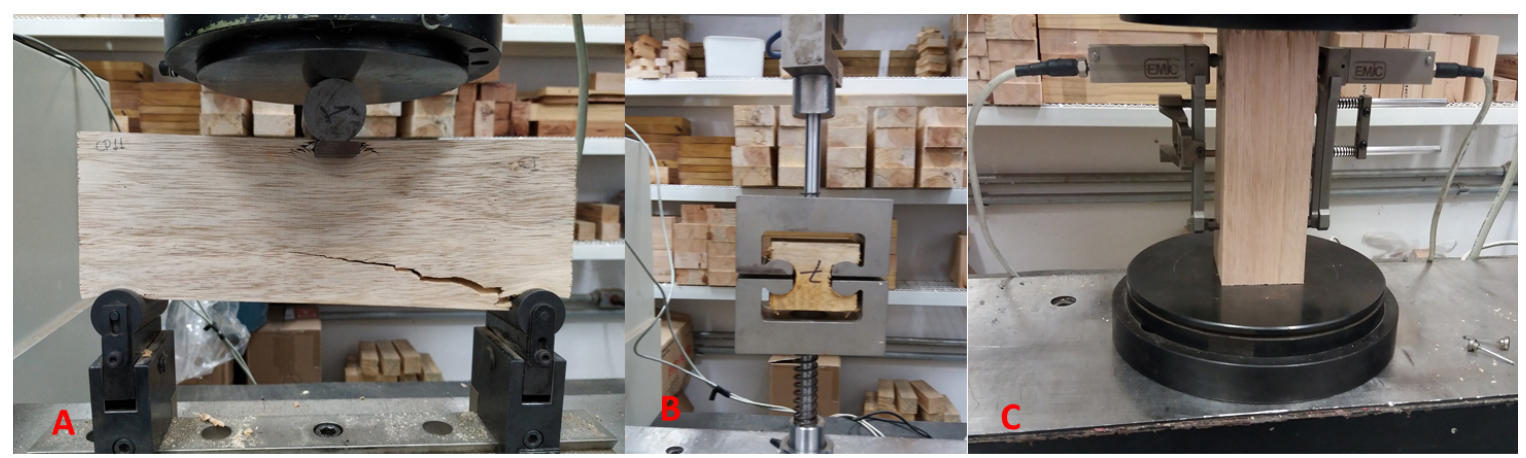

Figure 3. A - Bending test - ISO 13910 (2005); B - Tensile test - ABTN NBR 7190 (1997); C - Compression test parallel to the grain - ABTN NBR 7190 (1997). 


\subsection{Numerical analysis}

Numerical simulations were carried out to estimate the stress distribution in the specimens, which was not possible to visually observe in the experimental tests. The numerical simulations also had the aim of identifying the failure modes obtained experimentally for the specimens. The ANSYS software used is based on the Finite Element Method (FEM).

For the wood specimen's discretization, the SOLID45 element was used (3D solids using 4-6 nodded elements with linear interpolation). The values of the mechanical properties of strength and elasticity of the woods were obtained by the experimental characterization tests.

The numerical evaluation was carried out from the application of the loads proposed in the experimental analysis. An orthotropic behavior was assumed for the woods (different mechanical properties for each of the three different orthogonal directions: longitudinal, radial, and tangential).

In ANSYS, for the ISO 13910 (2005) numerical model, the $\mathrm{z}$ coordinate axis corresponded to the longitudinal direction along the grain, the $\mathrm{y}$ axis to the radial direction, and the $\mathrm{x}$ axis to the tangential direction. In the numerical model based on the ABNT NBR 7190 (1997) standard, the $\mathrm{x}$ coordinate axis corresponded to the longitudinal direction along the grain and the $\mathrm{z}$ axis to the tangential direction.

The ABNT NBR 7190 specimen mesh was generated automatically by ANSYS, while the ISO 13910 (2005) specimen was divided into cubic elements of two millimeters (see Figure 4).

The relationships between the wood properties were admitted based on the work developed by Molina et al. (2019).
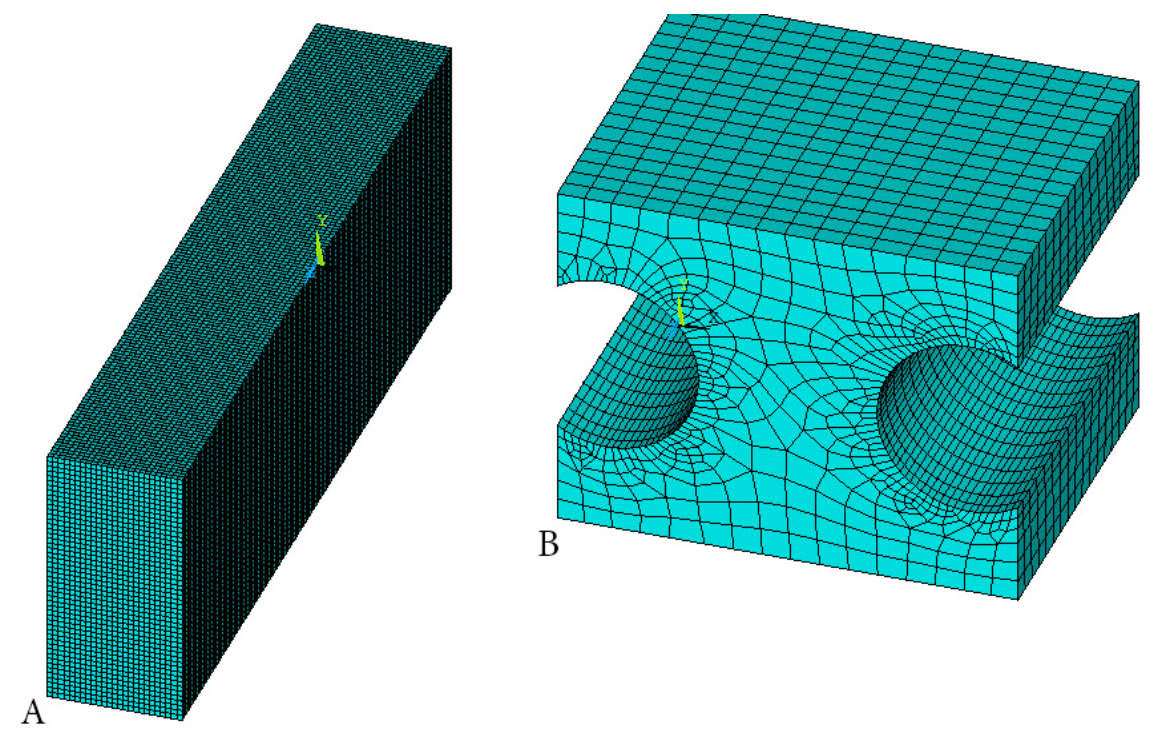

Figure 4. A - Mesh of ISO 13910 (2005) specimen; B - Mesh of ABTN NBR 7190 (1997) specimen.

\section{RESULTS AND DISCUSSION}

The $12 \%$ apparent density values obtained for the analyzed woods were: Indian Cedar $\left(\rho_{\text {ap }}=480 \mathrm{~kg} / \mathrm{m}^{3}\right)$ and Pine $\left(\rho_{\text {ap }}\right.$ $\left.=383 \mathrm{~kg} / \mathrm{m}^{3}\right)$. Table 1 shows the values obtained for tensile strength perpendicular to the grain for each wood species and test method, followed by the mean values $(\mu)$, sample standard deviation $(\sigma)$, and coefficient of variation $(C V)$.

Mascia et al. (2020) reported $f_{\text {t90 }}$ values ranging from $2 \mathrm{MPa}$ to $8 \mathrm{MPa}$, close to the values obtained from the ABNT NBR 7190 (1997) test method, while Schlotzhauer et al. (2019) reported strength values from 7.2 MPa to
10.6 MPa for small dimensions specimens according to the growth rings orientation.

The normality tests of the data indicated that the results presented normal distribution ( $\mathrm{p}$-value $>0.05$ ) with the exception of the compressive strength parallel to the grain of pine and bending tests according to ISO 13910 (2005) with cedar wood. The box-plot diagrams of the values obtained from $f_{\text {t90 }}$ are shown in Figure 5 (note that only the values obtained from the ISO 13910 (2005) method did not differ statistically). 
Table 1. Test results of wood tensile strength perpendicular to the grain $(U=12 \%)$.

\begin{tabular}{|c|c|c|c|c|c|c|}
\hline \multirow[b]{2}{*}{ Parameters } & \multicolumn{3}{|c|}{ Pine } & \multicolumn{3}{|c|}{ Cedar } \\
\hline & $\begin{array}{c}f_{t 90} \\
\text { NBR } 7190\end{array}$ & $\begin{array}{c}f_{t 90} \\
\text { ISO } 13910\end{array}$ & $\begin{array}{c}f_{c 0} \\
\text { NBR } 7190\end{array}$ & $\begin{array}{c}f_{t 90} \\
\text { NBR } 7190\end{array}$ & $\begin{array}{c}f_{t 90} \\
\text { ISO } 13910\end{array}$ & $\begin{array}{c}f_{c 0} \\
\text { NBR } 7190\end{array}$ \\
\hline$\mu(\mathbf{M P a})^{*}$ & 2,72 & 0,95 & 22,77 & 3,67 & 1,06 & 46,56 \\
\hline$\sigma(\mathrm{MPa})$ & 0,54 & 0,14 & 3,56 & 0,90 & 0,35 & 6,04 \\
\hline CV (\%) & $19,80 \%$ & $14,27 \%$ & $15,65 \%$ & $24,57 \%$ & $32,89 \%$ & $12,97 \%$ \\
\hline Characteristic value (MPa) & 2,23 & 0,82 & 18,10 & 2,44 & 0,68 & 40,89 \\
\hline
\end{tabular}

${ }^{*}$ Average of 40 specimens

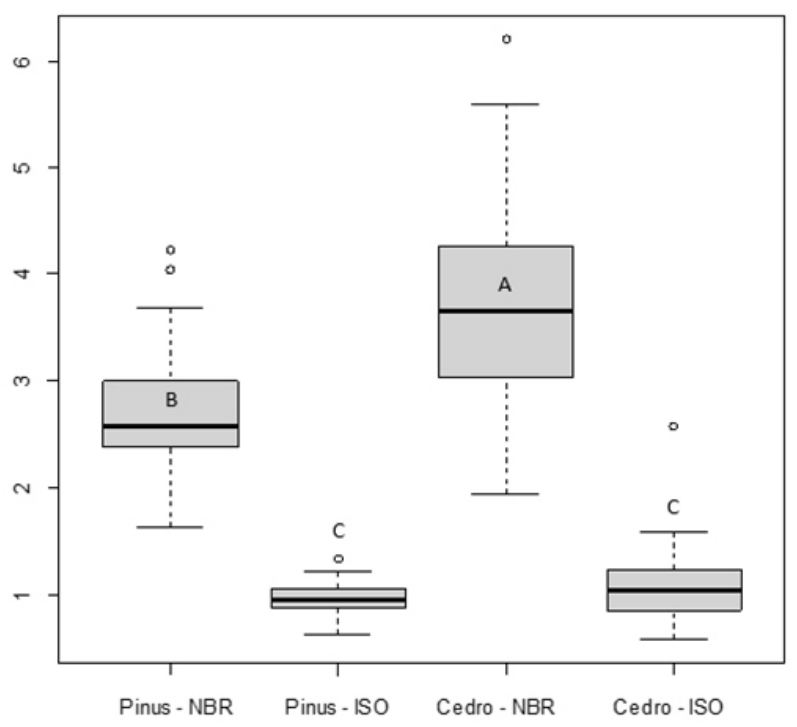

Figure 5. Box-plot of $f_{\text {t90 }}$ values obtained. Y-axis shows the normal tensile strength in MPa. Same letters indicate that there was no significant difference.
The simplified ratios $\left(f_{\mathrm{t} 90 \mathrm{k}} / f_{\mathrm{cok}}\right)$ are shown in Table 2 . The values of these ratios ranged from 0.017 to 0.123 , indicating the low value of this property when compared to the compressive strength parallel to the fibers, used for structural design.

Table 2. Simplified relationships $\left(\mathrm{f}_{\mathrm{t} 0 \mathrm{k}} / \mathrm{f}_{\mathrm{cok}}\right)$ obtained for each of the tested combinations

\begin{tabular}{ccc} 
Woods & NBR 7190 & ISO $\mathbf{1 3 9 1 0}$ \\
\hline Pine & 0,123 & 0,045 \\
Cedar & 0,060 & 0,017 \\
\hline
\end{tabular}

The most common failure mode obtained for the ABNT NBR 7190 (1997) specimens is shown in Figure 6. The failure mode observed in the specimens tested according to the Brazilian standard was the separation of the fibers perpendicularly to the longitudinal direction in the cut section (Figure 6a). There was a concentration of stresses in the central region of the specimen, which was responsible for the rupture of the specimen during the test, as seen in Mascia et al. (2020).
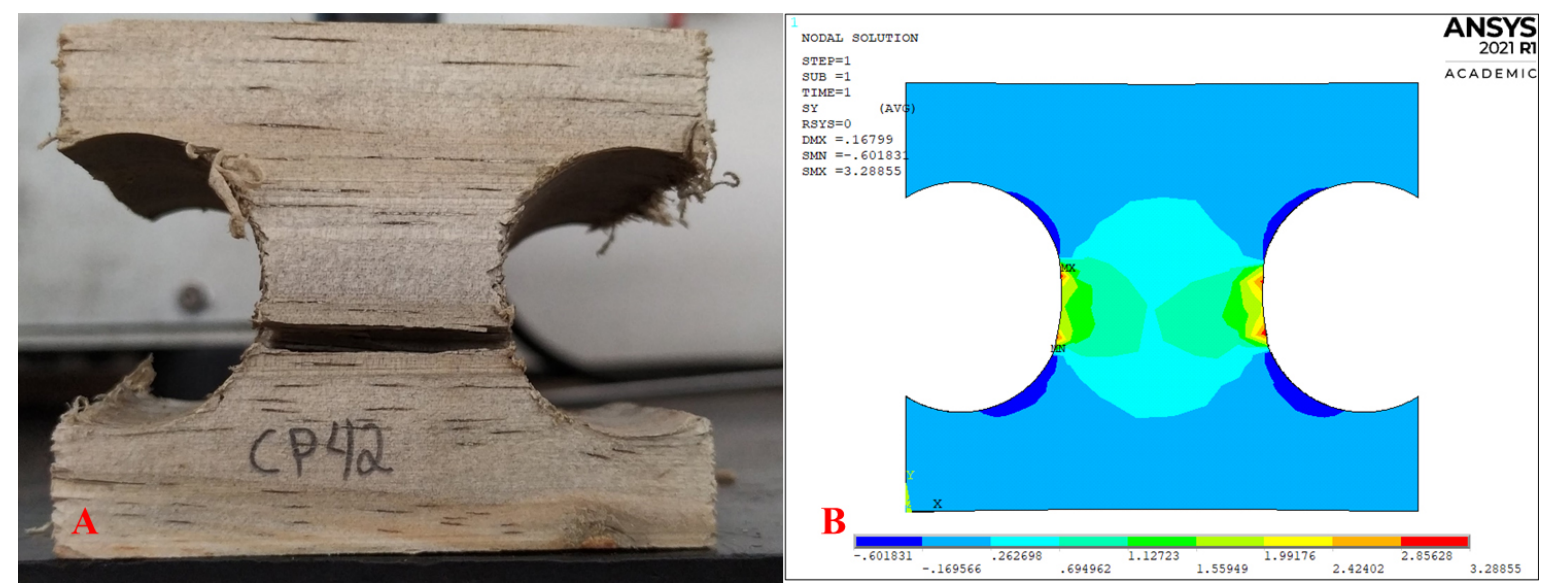

Figure 6. A - Fiber separation perpendicularly to the longitudinal direction; B - Normal tensile stress on the Y axis, in MPa.

For the specimens tested by the ISO 13910 (2005) standard, three main rupture modes were observed:

(1) Rupture by inclined shear starting from the support (Figure 7a);
(2) Failure by tension of the lower fibers (Figure $7 \mathrm{~b}$ ).

(3) Shear close to the neutral line of the cross-section along the length of the specimen (Figure 7c); 


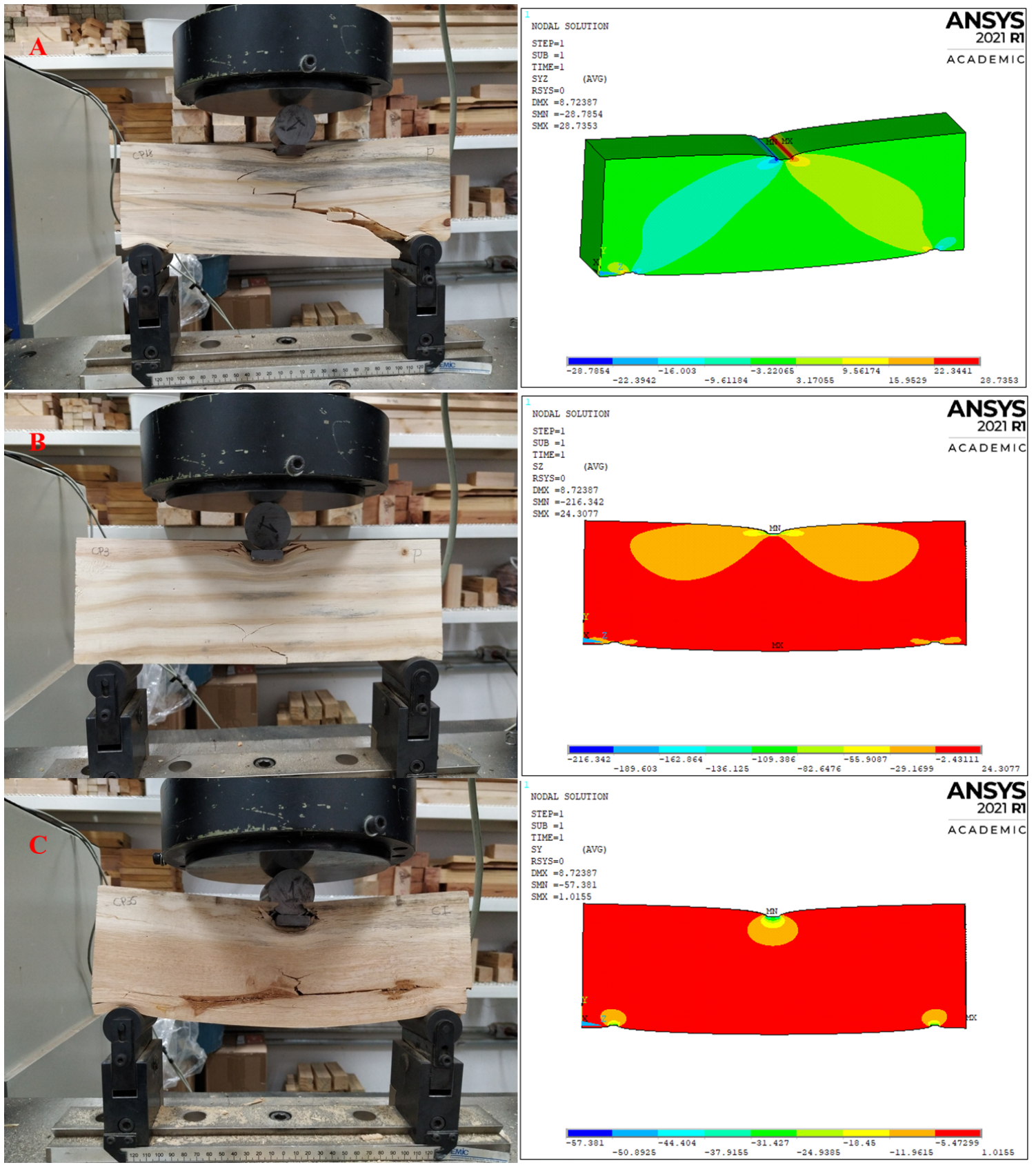

Figure 7. A - Inclined shear failure in relation to the fibers (Shear stresses in the yz plane in MPa); B - Tensile failure in the lower fiber of the beam (Normal stresses in the $\mathrm{z}$-axis in $\mathrm{MPa}$ ); C - Shear failure at the neutral line of the section (Normal stresses on the $\mathrm{y}$ axis in MPa).

The rupture mode of the test specimens tested based on the ISO 13910 (2005) depended on the type of wood, as seen in Figure 8. Failure due to rupture in the supporting regions was predominant in the pine specimens (Type A failure mode - Figure 7), while the cedar wood specimens had a failure due to tension in the lower fiber (Type B failure mode - Figure 7). Neutral line shear failures (Type B failure mode - Figure 7) occurred in only two specimens of each species.
In pine wood, the predominant failure mode was Type A (70\%), followed by Type B (25\%) and then Type C (5\%). In cedar wood, the predominant failure mode was Type $\mathrm{A}$ (50\%), followed by Type B (45\%) and then Type C (5\%). The $f_{t 90}$ values were influenced by the type of failure in cedar wood, where specimens that failed due to traction had higher strength values, while in pine wood there was no effect of the type of failure on strength. 

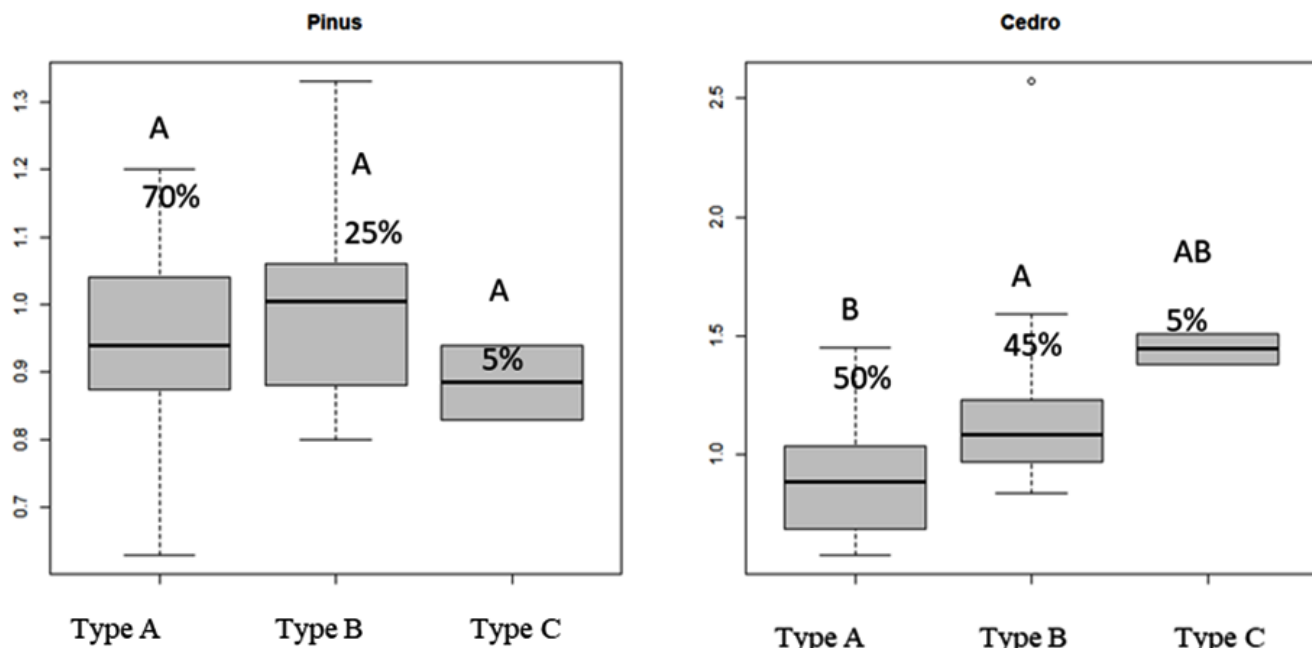

\section{$\begin{array}{lll}\text { Type A } & \text { Type B } & \text { Type C }\end{array}$}

Figure 8. Box-plot of $f_{\mathrm{t} 90}$ according to each type of failure (proportions in percentage). Y axis is $f_{\mathrm{t} 90}$ in MPa. Same letters indicate that there was no significant difference between the results.

\section{CONCLUSIONS}

The methodology of ABNT NBR 7190 (1997) generated different results of strength perpendicular to the grain (between 2,72 MPa to 3,67 MPa) for each species of wood. These values were superior to those obtained by the methodology of ISO 13910 (2005) (between 0,95 MPa and 1,06 MPa), which were not affected by wood species.

The methodology proposed by ABNT NBR 7190 (1997) results in pure tension perpendicular to the fibers. Thus, the rupture mode is restricted to occur in the central section of the specimen and tends to present higher values when compared to the ISO 13910 (2005) standard.

The specimen adapted from ISO 13910 (2005), with the fiber direction parallel to the length of the specimen, presented three different types of failures. The specimens made from pine wood showed predominant rupture ( $70 \%$ of cases) by inclined shear starting from the supports, while the specimens made from cedar wood showed two predominant types of rupture: by inclined shear starting from the supports and due to traction in the lower fiber of the specimen.

The proposed numerical models were able to reproduce the stress distribution in the test specimens tested, with reasonable approximation, complementing the experimental results and identifying the failure modes obtained.

The $f_{\mathrm{t} 90 \mathrm{k}} / f_{\mathrm{cok}}$ ratios ranged between 0,017 and 0,123 for both analyzed standards, once again proving the low strength of wood in tension perpendicular to the grain.

\section{SUBMISSION STATUS}

Received: 25 Sept. 2021

Accepted: 25 Nov. 2021

Associate editor: Geraldo Bortoletto Junior (D)

\section{CORRESPONDENCE TO \\ João Vítor Felippe Silva}

Faculdade de Engenharia de Guaratinguetá - UNESP, Av. Dr. Ariberto Pereira da Cunha, 333, CEP 12516-410, Guaratinguetá, SP, Brasil e-mail: jvf.silva@unesp.br

\section{AUTHORS' CONTRIBUTIONS}

João Vítor Felippe Silva: Formal analysis (Equal); Software (Equal; Validation (Equal); Writing - original draft (Lead); Writing - review \& editing (Equal).

Patrik Luiz Silva de Araujo: Investigation (Lead), Methodology (Equal), Visualization (Equal).

Karina Aparecida de Oliveira: Formal analysis (Equal), Writing original draft (Equal), Writing - review \& editing (Equal).

Maria Fernanda Felippe Silva: Formal analysis (Equal), Software (Equal), Writing - original draft (Equal).

Carolina Aparecida Oliveira: Investigation (Equal), Methodology (Equal), Writing - review \& editing (Equal).

Julio Cesar Molina: Conceptualization (Lead), Formal analysis (Equal), Funding acquisition (Equal), Software (Supporting), Supervision (Lead), Validation (Equal), Writing - original draft (Equal), Writing - review \& editing (Equal).

\section{REFERENCES}

Almeida JPB, Aquino VBM, Wolenski, ARV, Lahr, FAR, Christoforo AL. Analysis of relations between the moduli of elasticity in compression, tension, and static bending of hardwood. BioResources 2020; 15(2): 3278-3288.

Associação Brasileira de Normas Técnicas. NBR-7190: Projeto de Estruturas de Madeira. Rio de Janeiro; 1997.

Bidakov AM, Raspopov IA. Test method of CLT by tension perpendicular to grain. Academic Journal. Series: Industrial Machine Building, Civil Engineering 2018; 1(50): 148-158. 
Costa LJ, Lopes CBS, Reis MFC, Paula MO, Figueiró CG, Fialho LF et al. Effect of Sample Dimensions on Static Bending Test. Floresta e Ambiente 2020; 27(1): e20170996.

International Standard. ISO-13910: Structural timber Characteristic values of strength-graded timber - Sampling, fullsize testing and evaluation. Switzerland; 2005.

Mascia NT, Kretschmann DE, Ribeiro AB. Evaluation of Tension Perpendicular to Grain Strengths in Small Clear Samples of Sugar Maple for Radial, Tangential and 45-Degree Loading Directions. Materials Research 2020; 23(3): e20190323.

Matos GS, Molina JC. Resistência da madeira ao cisalhamento paralelo às fibras segundo as normas ABNT NBR 7190:1997 e ISO 13910:2005. Revista Matéria 2016; 21(4):1069-1079.

Molina JC, Calil Junior C, Oliveira DR, Gomes NB. Analytical, experimental and numerical study of timber-concrete composite beams for bridges. Computers and Concrete 2019; 24(2):103-115.
Reis AHS, Silva DW, Vilela AP, Mendes RF, Mendes LM. Physicalmechanical Properties of Plywood Produced with Acrocarpus fraxinifolius and Pinus oocarpa. Floresta e Ambiente 2019; 26(4): e20170157.

Rocha MFV, Costa LR, Costa LJ, Araújo ACC, Soares BCD, Hein PRG. Wood Knots Influence the Modulus of Elasticity and Resistance to Compression. Floresta e Ambiente 2018; 25(4): e20170906.

Schlotzhauer P, Ehrmann A, Bollmus S, Militz H. Critical discussion of perpendicular to grain tension testing of structural timber - case study on the European hardwoods ash, beech and maple. Wood Material Science \& Engineering 2019; 15(5):278-288.

Tanaami RG. Tração normal Às fibras em peças de madeira [Tese]. São Carlos: Escola de Engenharia de São Carlos, Universidade de São Paulo; 1993.

Wu QY, Niu S, Wang HJ, Jin YB, Zhu EC. An investigation of the DOL effect of wood in tension perpendicular to grain. Construction and Building Materials 2020; 256: 119496. 